Case Report

\title{
Utilization of awake craniotomy for supra-tentorial tumor resection during pregnancy: A technique useful for fetal-maternal wellbeing
}

\author{
Dileep Kumar' ${ }^{1}$ Sheema Siraj², \\ Khalid Ahsan', Faraz Shafiq ${ }^{4}$
}

\begin{abstract}
Meningioma is the benign tumor that can also occurs during pregnancy. We are reporting a case of 29 years, 13th weeks pregnant lady, who underwent supratentorial craniotomy using awake through out approach. The case report highlights the challenges we faced during anaesthetic management, which includes psychological preparation, institution of scalp block and successful neurological monitoring. Technique proven to be useful considering pregnancy related physiological and tumor related pathological changes, the impact of which lies directly on maternal \& fetal wellbeing.
\end{abstract}

KEYWORDS: Pregnancy, Supratentorial, Craniotomy and Wakefulness.

doi: https://doi.org/10.12669/pjms.36.2.1853

How to cite this:

Kumar D, Siraj S, Ahsan K, Shafiq F. Utilization of awake craniotomy for supra-tentorial tumor resection during pregnancy: A technique useful for fetal-maternal wellbeing. Pak J Med Sci. 2020;36(2):293-295. doi: https://doi.org/10.12669/pjms.36.2.1853

This is an Open Access article distributed under the terms of the Creative Commons Attribution License (http://creativecommons.org/licenses/by/3.0), which permits unrestricted use, distribution, and reproduction in any medium, provided the original work is properly cited.

\section{INTRODUCTION}

Meningioma rarely presents in pregnancy. Once appeared, their growth rate is relatively increased. ${ }^{1}$ Neurosurgical intervention is usually required when patient develops instability, worsening of cranial pathology on imaging studies and at times during pregnancy. ${ }^{2}$ The choice between general anaesthesia (GA) versus awake craniotomy

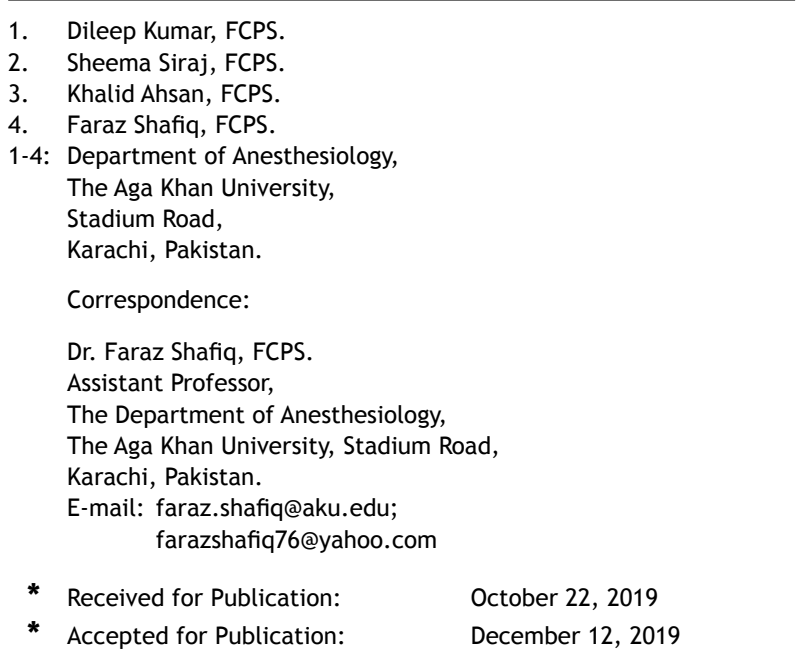

(AC) is based on location of tumor and need of intraoperative neurological monitoring. However, patient's motivation, available expertise and fetalmaternal wellbeing are additional factors which needs to be considered in this scenario. We are reporting a successful management of gross total resection of meningioma in pregnant lady using AC. The case report highlights the importance of awake throughout (AT) approach in terms of patient's acceptance, neurological outcome and fetal-maternal well-being.

\section{CASE}

Our patient was 29-year Asian female. She was gravida 3 and para $2+0$, weighing $53 \mathrm{Kg}$ and height of $153 \mathrm{~cm}$. She presented at $13^{\text {th }}$ weeks of gestation with complaint of "Left eye blurred vision" since seven months. Past medical and obstetric history was insignificant. She noticed aggravation of her symptoms since 4 th week of gestation. The Magnetic resonance imaging (MRI) brain revealed broad based extra-axial lesion in right frontal region causing marked mass effect on adjacent brain parenchyma. The provisional diagnosis was 
"Right frontal meningioma". The neurosurgical team selected this patient for AC. Primary anaesthetist did preoperative assessment and psychological counseling. The pre-operative GCS was 15 , and she had no neurological deficits except left sided blurred vision. Her hemoglobin was $11.6 \mathrm{~g} / \mathrm{dl}$, while hematocrit of $35.1 \%$, for which she was labeled American Society of Anesthesiologist (ASA) grade II. The pelvic ultrasound was evident for alive $13^{\text {th }}$ weeks fetus. Obstetric monitored fetal heart sounds preoperatively, and administered cyclogest $800 \mathrm{mg}$ rectally as a tocolytic agent. Routine ASA specified monitoring including EKG, pulse oximeter was done. Left radial artery cannulation was done for continuous blood pressure monitoring. The scalp block was instituted to provide intraoperative analgesia. This was done using anatomical landmark technique. ${ }^{3}$ The supplemental oxygen at two liters per minute via nasal prongs with inbuilt EtCO2 monitoring was applied. Once the effectiveness of scalp block was confirmed the patient's head was fixed on Mayfield frame. Supra-tentorial craniotomy was performed. Patient remained comfortable and co-operative through out the procedure. Intraoperative neurological assessment was done for contralateral motor functions in both upper \& lower limb. The surgery lasted for four hours during which gross resection of tumor was done. Estimated blood loss was the $600 \mathrm{ml}$. After the completion of surgery, patient was shifted to post anaesthesia care unit (PACU) with stable hemodynamics. The postoperative analgesia was provided using intermittent doses of Paracetamol and Tramadol. Post procedure obstetric review ensured fetus viability as evident by fetal heart sounds. Overall patient remained fairly stable and was discharged to home on 3rd postoperative day. Her follow up after one week revealed complete resolution of symptoms. The provisional diagnosis of meningioma was confirmed on histopathology.

\section{DISCUSSION}

Meningioma is one of the most common benign tumors that occur during pregnancy. Its occurrence during pregnancy is not different from adult population comprising about $20 \%$ of all brain tumors, with an incidence of 5-6 per 100,000 pregnancies. ${ }^{4}$ However, studies have shown relationship between tumor growth and hormonal changes associated with pregnancy. These hormonal changes may be the reason of flaring up of symptoms during pregnancy. ${ }^{5}$ Neurosurgical intervention during pregnancy means massive alteration in patient's physiology. One need to understand the physiological changes associated with pregnancy, and pathological consequences of tumor on cerebral physiology. Besides, an impact of anaesthetic technique on feto-maternal circulation needs to be considered. The use of AC in this scenario is logical not only to avoid GA and harmful effects of anaesthetic medications, but it also enhances recovery. The corner stone of anaesthetic management is preoperative psychological preparation and assessment of willingness from patient. The involvement of primary anaesthetist is helpful not only in reducing the anxiety but also for rapport building.

The additional challenge that we faced was her language barrier status. Preoperative counseling of patient was done with the help of translator that helped her in clear understanding about technique, possible discomforts and the need of being awake. Patient remained hemodynamically stable and pain free during the procedure. Besides, intraoperative neurological monitoring was done successfully which was helpful in doing gross total resection. The AT approach is routine at our health care setup. The technique has proven to be safe, very low complication rates including the conversion to GA. Similarly, it's been used patients having variable socioeconomic and educational backgrounds, as well as having different co-morbidities.6 The success of this in pregnancy is addition to its applicability. Though studies have shown some association with preoperative anxiety and postoperative pain in patients recently diagnosed to have brain tumours. ${ }^{7}$ However, preoperative psychological preparation and perioperative support throughout the procedure is important to make this technique successful. This is evident by the fact that most patients have no recall about the intraoperative discomfort and declare better satisfaction postoperatively. ${ }^{8}$ Postoperative review of our patient also showed better satisfaction with the technique.

\section{CONCLUSION}

Awake Through (AT) approach is logical and safe in pregnant patients requiring tumor resection during pregnancy. Anaesthetic management includes extensive preoperative psychological preparation and intraoperative use of scalp block. The technique provides hemodynamic 
stability, facilitates intraoperative neurological monitoring, tumor resection and improving fetalmaternal outcome.

Grant Support \& Financial Disclosures: None.

\section{REFERENCES}

1. Hortobagyi T, Bencze J, Mrnyak B, Kouhsari MC, Bognar L, Marko-Varga G. Pathpphysiology of Meningiona growth in preganancy. Open Med (Wars). 201713;12:195-200. doi: 10.1515/med-2017-0029.

2. Abd-Elsayed AA, Diaz-Gomez J, Barnett GH, Kurz A, IntonSantos M, Barsoum S, et al. A case series discussing the anaesthetic management of pregnant patients with brain tumours. Version 2. F1000Res. 2013;2:92. doi: 10.12688/ f1000research.2-92.v2

3. Shafiq F, Salim F, Enam A, Parkash J, Faheem M. Anaesthetic management of supratentorial tumor craniotomy using Awake - Throughout approach. J Coll Physicians Surg Pak. 2017;27(12):775-777.

4. Gurcay AG, Bozkurt I, Senturk S, Kazanci A, Gurcan O, Turkoglu OF, et al. Asian J Neurosurg. 2018;13(1):86-89. doi: 10.4103/1793-5482.181115

5. Dumitrescu BC, Tataranu LG, Gorgan MR. Pregnant woman with an intracranial meningioma - case report and review of the literature. Rom Neurosurg. 2014;21:489-496
6. Shafiq F, Parkash J, Enam A, Khan MF, Baiq T. An awake through out approach for awake craniotomy: A perspective form a resource limited country. World Neurosurg. 2019;126:e1489-e1493. doi: 10.1016/j.wneu.2019.03.127.

7. Goebel S, Stark AM, Kaup L, von Harscher M, Mehdorn HM. Distress in patients with newly diagnosed brain tumours. Psycho-oncology. 2011;20:623-630.

8. Beez T, Boge K, Wager M, Whittle I, Fontaine D, Spena G, et al European Low Grade Glioma Network Tolerance of awake surgery for glioma: a prospective European low grade glioma network multicenter study. Acta Neurochir 2013;155:1301-1308.

\section{Authors Contribution:}

DK: Preoperative preparation, perioperative care, initial write up.

SS: Case summary write up, consent from the patient, finalization of author Performa.

KA: Supervision during the clinical care being the credential for service.

FS: Literature search, Discussion, Proof reading, submission, is responsible for integrity of research. 